\title{
Taking Science to Festivals: Engaging the Public Where They Least Expect It
}

\author{
Connie Potter ${ }^{1}$ \\ CERN \\ Geneva, Switzerland \\ E-mail: Connie.Potterecern.ch
}

\section{Roger Jones}

Lancaster University

Lancaster, United Kingdom

E-mail: roger.jones@ern.ch

\begin{abstract}
Over the past several years, a team based around the ATLAS Experiment at CERN in Geneva has organised public engagement and education activities, not only at events with an explicit science mandate, such as the Bluedot Festival (at Jodrell Bank, UK), but also at a variety of nonscientific venues. These have included the Montreux Jazz Festival (Montreux, Switzerland), the WOMAD Festival (Charlton Park, UK), Moogfest (Durham, NC, USA), and the Sofia Music Weeks in Bulgaria, with discussions on-going with a major European music festival as well as a festival in the United States. The goal of this effort is to engage new audiences that normally would not be drawn to science events and to investigate our ability to communicate scientific messages to diverse audiences. The results have been impressive, as measured through attendance (for example: the first Physics Pavilion at WOMAD received 4500 visitors over 3 days and its successor in 2017 over 5500), and enthusiasm of the audience and the scientists hosting the activities. We describe the presentation material and format, the hands-on workshops, and other methods employed, as well as lessons learned on how to best optimise audience engagement. The concept can be reproduced for other festival-type environments, and adapted to suit the particular audience demographic and format of the festival.
\end{abstract}

Sixth Annual Conference on Large Hadron Collider Physics (LHCP2018)

4-9 June 2018

Bologna, Italy

\section{${ }^{1}$ Speaker}




\section{Introduction}

The particle physics community has a good track record of effective outreach within the confines of science venues and events, i.e. science festivals and museums, school science classes and open-door events at scientific establishments. These attract those already interested and at some level committed to science. However there remains a significant proportion of the general public who have been somewhat neglected by mainstream physics outreach efforts. Within this category, there are two very important groups. The first is those who are young, still at school, and are unsure of pursuing physics for further study. The second group is those who feel that physics is 'not for them', they tried it at school and understood so little that they either felt stupid or were just too bored to continue, so they gave up. In this paper we will discuss our attempts over the past 3 years to reach this untapped part of the population, by taking the physics to where they themselves like to spend their relaxation time, alone, with friends or with family: the phenomenon that is the music and culture festival.

\section{Scope}

The words "music festival" usually conjure up images of the "60s hippy era, tents and mud. However they began much earlier, with events such as the Bayreuth Festival started in 1896 by the composer Wagner. Since then we have seen legendary festivals such as Monterey, Woodstock and the Isle of Wight in the " $60 \mathrm{~s}$ and ' $70 \mathrm{~s}$, which in turn spawned long-running series of festivals such as Glastonbury, Pinkpop, Lollapalooza and hundreds of others up to the present day. New festivals are appearing every year, with audiences ranging from 5'000 to $200^{\prime} 000$ people. They cater for every type of music and attendees' ages range from 5 to 95 years. In light of fierce competition, festivals are adding additional dimensions such as art, culture and literature to their offering. They attract broadly the same audience as before, but they are offered a wide range of non-musical activities and events, usually during the day time when there are fewer music performances. As the founder of the Port Eliot Festival in England described his festival "It's aimed at stimulating the brain all day and partying all night" [1]. It is into this framework that since 2015 we have introduced science.

\section{WOMAD Festival}

Founded over 30 years ago in England by the musician Peter Gabriel, the W.O.M.A.D festival (World Of Music Art \& Dance) now extends to several continents, with the U.K. edition remaining the flagship. That flagship event runs over 3.5 days and welcomes on average $30^{\prime} 000$ people through its gates, with many repeat visitors. The festival now has a very useful App through which visitors are able to create their own personal schedule, thereby offering organisers an insight into what is trending even before the festival begins.

\subsection{The Pavilion}

The tented space called The Physics Pavilion holds 220 seats, a large, fully-equipped stage, and standing space at the back. Presentations are scheduled hourly from $12 \mathrm{~h}$ to $18 \mathrm{~h}$ (recently extended in both directions due to popular demand), each lasting approximately 40 minutes, with 10 minutes for questions. Along with talks, a live link has been scheduled each year, with a variety of partners, most recently NASA Houston and NASA Goddard. 


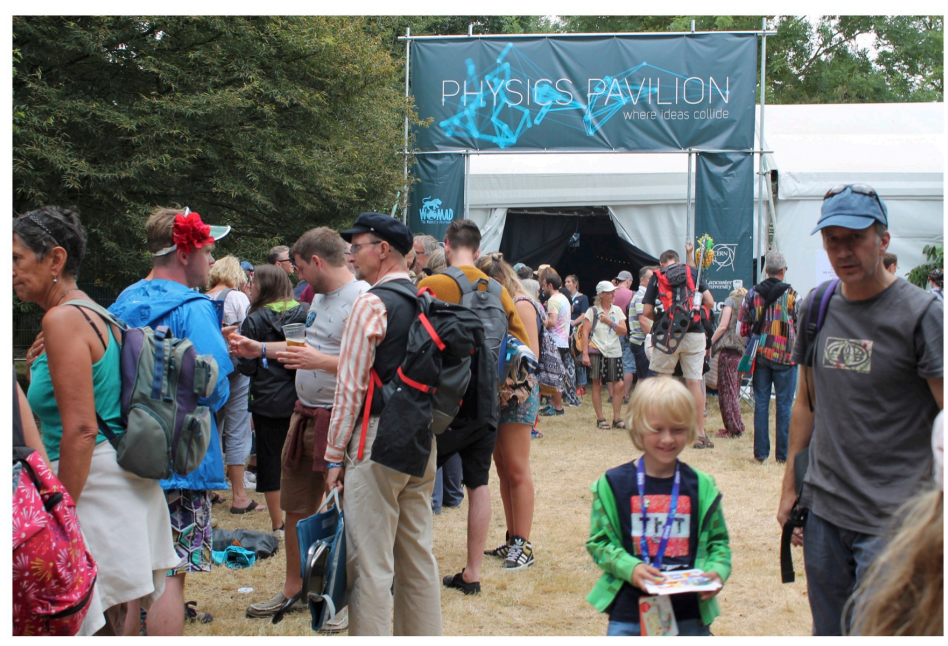

Fig. 1: Entrance queue to the Physics Pavilion at the WOMAD

\subsection{The Lab}

After the hugely successful inaugural year of 2016, WOMAD offered two new spaces, the largest of which, christened The Lab, is uniquely for hands-on ticketed workshops. In order to deal with potential 'no-show' issues, tickets are only given out on the door 30 minutes before the start of each workshop. The range of workshops is wide, from programming robots to soldering badges to making planetary systems with paper, glue and felt to the Physics of Gin and learning and creating Science Rap. Some require far more infrastructure than others, but as partnerships grow, it becomes easier to borrow equipment as well as volunteers.

\subsection{The Gazebo and Welcome Spaces}

In addition to the Lab, an open-fronted tent and other small attractions were introduced into the 'welcome area' in front of and between the Pavilion and the Lab. The open fronted tent was christened the Gazebo, and is used for a rotating set of interactive, 'walk up' experiences. These included Virtual Reality tours of the CERN underground areas, puzzles and tasks set by teams from the Institute of Physics and from the household goods manufacturer, Dyson. These were joined by other small attractions, such as the opportunity for a 'selfie' to be taken in front of an LHC tunnel backdrop, a mini camera obscura, and an 'ask a physics question' booth. The motivation behind all these features was to attract passers-by, drawing them towards the main events, and to entertain queues that formed for those main events.

Equally important in that space were the helpers, who managed the queues, handed out stickers (which were used to estimate footfall) and interacted with the attendees. From the feedback, these interactions were an important part of the audience engagement.

\subsection{Personnel and Logistics}

Personnel are a key part of any event in which interaction with the public is involved. In this case, the team are even more important because they are representing a subject that can often daunt or intimidate the general public, and the first contact festival-goers have is with the team- 
members themselves. It is crucial to select them well, brief them well, give some key words and explanations in simple, engaging terms and ensure they retain a light-hearted, friendly approach at all times. All are volunteers, giving up their time willingly, and strongly believe in the process and the aims of the event. It is not unusual to often hear it said by the volunteers 'this is the best outreach I have seen for a long time'. Equally, speakers are extremely enthusiastic, as told by a Professor at Univ. College London 'Its changed the way I teach and speak to students. I've been able to take more risks..' [2]

Additionally, the fact that the volunteers come from different organizations, in this case CERN, Lancaster University, the Institute of Physics and friends and colleagues, creates a real sense of combined purpose and partnership.

As regards logistics, the word 'partnership' again comes strongly into the equation, with the WOMAD organization contributing enormously in terms of infrastructure and technical personnel, accommodation and some equipment. With workshops such as Build Your Own Cloud Chamber, WOMAD do not hesitate to rent blackout curtains for the full Lab space.

\subsection{Monitoring Success and Impact}

As with all outreach, monitoring the success and impact is difficult but essential. The footfall was monitored by the handing out of stickers (each specific to the Pavilion and the Lab). Feedback was solicited both on paper and via the internet; of these, the paper feedback was still the most plentiful and effective. There was also a 'pin board' where young and old could attach stickers to areas corresponding to responses to feedback questions. Unsurprisingly, this was most effective for capturing the feedback from the very young.

With the advantage of running over several years, some evidence for lasting impact was starting to emerge. In particular, some families, typically under pressure from younger members, were planning much of their Festival visit around the Physics area, showing a lasting engagement. There was also some evidence of a heightened interest in science between the events.

\section{Prospects}

With these initial events, a basic toolkit has been created that can be deployed in part or as a whole to other festivals. Requests from other festivals worldwide have been received and discussions are well underway.

The key elements are to choose an enthusiastic and engaged team of both volunteers and speakers; to partner with local institutions who can provide both effort and funding; and to ensure that the festival itself is committed to supporting the activity. The experience thus far shows that there is a genuine appetite for science in the broader festival-going public, which needs to be addressed.

\section{References}

[1] L. Baker, Why Music Festivals Won't Die, BBC.com [http://www.bbc.com/culture/story/20150622-why-music-festivalswont-die]

[2] M. Vennard, The festivals mixing music and science, BBC.com [https : //www.bbc.co.uk/news/science-environment-45284935] 